\title{
An Exploration on the Attachment, Acculturation, and Psychosocial Adjustment of Chinese International Students in Japan
}

\author{
Mengxi Yin \\ Cleveland State University, USA \\ Kikuyo Aoki \\ Ochanomizu University, Japan \\ Kelly Yu-Hsin Liao \\ Cleveland State University, USA \\ Hui Xu \\ Loyola University Chicago, USA
}

\begin{abstract}
In this study, we selected Chinese students $(N=277)$ studying in Japan as research participants to examine the relation among their attachment, acculturation, and psychosocial adjustment. The study's first finding revealed that Chinese students studying in Japan had a better adjustment outcome than those in America in terms of sociocultural adjustment but not psychological adjustment. The second set of findings from the results of hierarchical multiple regression analyses showed that psychological distress and sociocultural adjustment could be predicted by attachment anxiety and avoidance. Third, we found a positive correlation between acculturation to the host culture and sociocultural adjustment difficulties. Fourth, we did not find a correlation between acculturation to the host culture and attachment anxiety and avoidance. We offer a discussion on the findings and limitations in light of the unique Japanese sociocultural context.
\end{abstract}

Keywords: acculturation, attachment, Chinese international students, Japan, psychosocial adjustment 


\section{Introduction}

Higher education has seen a rapid rise in Chinese students enrolling in institutions in many countries like America and Japan (Organisation for Economic Cooperation and Development, 2017). This population is becoming the biggest group of international students, which causes the psychological well-being and cultural adaptation of Chinese international students to receive extensive attention. Research has been carried out to examine the joint issue of mental health and cultural adaptation in the context of Western individualism, but little research has been conducted to investigate the similar phenomenon in the collectivistic context of eastern countries (Ward \& Lin, 2010). That is, the majority of the research studies to date on Chinese international students have been conducted in the United States, which values individualism and is the top destination for Chinese international students (Hofstede, 1980). The relationships between the cultural adaptation and mental health of Chinese international students may not be the same in individualistic and collectivistic contexts, which have different expectations and norms for the acculturation of Chinese international students. We chose Japan as the country to represent the collectivist context because it is the top destination in Asia for Chinese international students and has been intensively studied as an example of collectivist culture (Bond, 2002). Moreover, not enough is yet known about international students' adjustment issues in Japan from empirical journals (Lee, 2017).

The acculturation issues of Chinese international students are cross-culturally universal and special in collectivistic contexts (Ge, 2007; Ma, 2007), which is an important issue not only for an expanded theoretical understanding of acculturation in cross-cultural settings, but also teachers, helping professionals, and policy makers in collectivistic contexts. Among the studies on the acculturation of Chinese international students, modes of acculturation based on Berry's acculturation framework (Berry et al., 1987) and attachment based on attachment theory (Bowlby, 1988) appeared to be two important theoretical frameworks that were conducive to predicting the psychological outcomes of the acculturation process (e.g., Chen et al., 2002; Hayashi, 1997; Sun, 2013; Wang \& Mallinckrodt, 2006). Therefore, our primary research question is: How do acculturation modes and attachment affect the acculturation process of Chinese students studying in Japan? Additionally, what is the difference in psychosocial adjustment between Chinese international students in Japan and Chinese/Taiwanese international students in the United States? Built on these research questions, we developed the following hypotheses:

Hypothesis 1: Chinese students studying in Japan would have a better adjustment outcome than those in the United States in both sociocultural and psychological domains.

Hypothesis 2: Greater identification with the home culture and adaptation to the host culture would exert a positive influence on the acculturation outcomes of Chinese students studying in Japan. 
Hypothesis 3: High attachment avoidance and anxiety would predict more psychological distress and difficulties in sociocultural adjustment.

Hypothesis 4: There would be a negative correlation between attachment anxiety and avoidance and acculturation to the host culture.

\section{Chinese International Students in Japan}

For a number of western countries, China was the largest source of international students, accounting for over $30 \%$ of the total in America, Canada, Australia, and New Zealand (Center for China and Globalization [CCG], 2018). The number of overseas Chinese students has been expected to grow continuously in terms of its population size and academic diversity (CCG, 2018). However, Chinese international students are often faced with a variety of challenges, including academic stress, academic uncertainties, general life difficulties, and cultural adaptation problems (Yeh \& Inose, 2003; Chen \& Zhou, 2019). The researchers also found that they were often vulnerable to psychological issues such as depression and anxiety, and underutilized counselling services. Therefore, understanding the academic and personal challenges of Chinese international students is of great importance to their academic performance and mental health, which has been extensively studied in individualistic contexts (e.g., the United States).

As noted previously, remarkably little research has examined the acculturation of Chinese international students in collectivistic contexts like Japan. Studying the acculturation of Chinese international students in the Japanese context has practical implications. Due to globalization and falling birth rate in Japan, the Japanese government has been striving to take positive measures to accept highly skilled foreign human resources and promising foreign students continuing higher education. The "300,000 Foreign Students Plan" was proposed by the Japanese government in 2008 with a view of increasing international students to 300,000 as of 2020 . Since then, the international student population has begun to increase rapidly and reached up to 267,042 by 2017 , giving Japan the biggest share in Asia (Japan Student Services Organization, 2018). The aforementioned policy not only increased the number of international students, but also encouraged universities to offer more courses taught in English and create opportunities like exchange student programs that place an emphasis on motivation, language abilities, and academic preparedness. A priority for colleges and universities in Japan is to think about how to provide the best support for international students' adaptation to a new environment and the demands of higher education. In order to help overseas students to adapt in Japan, researchers have focused on the acculturation of overseas students from a variety of aspects since 1989. However, fewer studies have been conducted in Japan that focus on the acculturation of international students in its cultural context compared with western countries that have a longer history of accepting international students (Ge, 2007). 
Chinese students, totaling 107,260 as of 20xx, constitute the largest subgroup of international students in Japan and have covered around or above half of the population since 1999 (JASSO, 2018). Individuals originating from a culture close to the host culture are likely to adapt well in the sociocultural domain (Ward et al., 2001), which may be associated with better psychological adjustment (Berry et al., 2006). China and Japan have been classified as collectivistic societies (Hofstede, 1993), and the cultural distance between China and Japan is considered to be close (Muthukrishna et al., 2018), thus the adaptation of Chinese students in Japan tends to be considered easier than that of students from Englishspeaking countries (Inoue \& Merino, 2007). Indeed, research on Chinese international students revealed that students report less difficulties in learning Japanese (Tanaka et al., 1994), and the similarities shared in daily life routines between China and Japan contribute to students' adaptation to some degree (Yin \& Aoki, 2017). However, when compared to their peers from other countries, cross-sectional research indicated that Chinese international students were faced with more sociocultural difficulties during the process of cultural adaptation and tended to suffer from more psychological distress than domestic students and international students from western countries (Ge, 2007; Ma, 2007). Research also highlighted that compared with domestic students, Chinese international students are less likely to initiate professional help-seeking behavior than domestic students (An \& Nagai, 2019). In particular, research suggested that in addition to gender, duration of stay, language proficiency, and other demographic characteristics, international students from China were challenged by the insufficient emotional support and friends from the host country, and limited support systems that are tailored to their needs (An \& Nagai, 2019; Wu, 2017). Jou and Fukada (2011) emphasized that despite the increase in the degree of total support for Chinese international students, the degree of stress perceived by the student group has increased. Following this, there is a critical need to develop interventions tailored to this student group.

In sum, overseas Chinese students are more likely to have difficulties in adapting to a new cultural environment, which thus highlights the need for targeted research attention and facilitation to this particular student group. So far, few studies have investigated the acculturation-related influence factors for the psychological well-being of this student group in Japan.

\section{Theoretical Framework}

Many experiences of Chinese international students can be understood within the framework of acculturation. Acculturation refers to both the process of adaptation and changes in psychology resulting from first-hand contact between individuals and/or groups from different cultural backgrounds (Berry et al., 1987). Berry and his colleagues (Berry et al., 1987) proposed a holistic model for acculturation, which has been widely used in contemporary studies on cultural adaptation. According to this model, the relation between acculturation and adjustment depends on five groups of moderating factors, including social nature, 
acculturating group type, individuals' social and demographic characteristics, and acculturation modes, as well as individuals' psychological characteristics.

When Berry et al.'s (1987) acculturation model was applied to Chinese international students, research predominantly focused on the modes of acculturation composed of integration, assimilation, separation, and marginalization. These modes were based on an orthogonal framework containing two cultural dimensions, namely attitudes toward the host and home cultures (Berry et al., 1987), each of which reflects a position on these two dimensions. Integration refers to highly identifying with host and home cultures; assimilation refers to highly identifying with the host culture, but weakly identifying with the home culture; marginalization refers to the opposite of integration on both dimensions; and separation refers to the opposite of both dimensions.

Conceptually, people who highly identify with both cultural dimensions (i.e., integration) were expected to show better psychosocial adjustment due to their ability to integrate two potentially conflicting cultures. Conversely, people who weakly identify with both cultural dimensions (i.e., marginalization) were expected to encounter psychosocial adjustment problems due to suffering from alienation with both host and home cultures (Berry et al., 1987; Bourhis et al., 1997). Research generally supported these theoretical predictions in individualistic cultural contexts. For example, Ward and Kennedy (1994) found that lower acculturation to the host culture predicted more difficulties in sociocultural adjustment, while strongly identifying with the home culture played a role in protecting mental health for a group of sojourners in New Zealand. Additionally, international students who highly identified with both cultural dimensions (i.e., integration) in America were found to experience less acculturative stress (Sullivan \& Kashubeck-West, 2015). Since extant research predominantly focused on individuals from collectivistic cultural backgrounds (e.g., China and Korea) in individualistic contexts (e.g., Canada and the United States), Berry et al.'s (1987) theoretical proposition and related research on the benefits of identifying with both host and home cultures were heavily contextualized in individualistic contexts, whose cross-cultural validity remains to be explored in collectivistic contexts. The cultural specificity of acculturation is important for the expanded understanding of acculturation in a global context and the practice of mental health counseling in specific contexts (e.g., Japan). Thus, this study also aimed to explore the effects of acculturation modes on the adjustment outcomes of Chinese students studying in Japan.

The acculturation of Chinese international students in Japan is not only an increasingly important issue, but also possibly exhibits a different acculturation process from that in an individualistic context. The difference is attributable to the fact that collectivist cultures have different expectations and provide different hosting environments for the acculturation of Chinese international students compared with individualistic cultures. For example, collectivistic contexts might emphasize identifying with the host culture (for instance, a Chinese saying "ruxiangsuisu" and a Japanese proverb "gou ni itte wa gou ni shitagae" in collectivistic contexts could be translated into "When in Rome, do as the Romans do") because within-group homogeneity is a valued norm in collectivistic contexts 
(Yasuda, 2011). Although Japan's government has made efforts in policy to represent a shift from a homogeneous-centered society toward a more pluralistic and diverse society, its effectiveness remains limited in the sociocultural level (Nagy, 2012). The pressure of identification with Japanese culture and the feeling of rejection from the host culture in its process have been highlighted in acculturation literature in Japan (e.g., Suzuki, 2007) especially among Chinese international students (Han, 2004; Yin \& Aoki, 2017). Relatedly, identification with host cultures in collectivistic contexts may overlap with identification with Chinese culture due to the cultural similarities between collectivistic contexts and Chinese culture, reducing the additive prediction of the two identification factors for the adjustment outcomes of Chinese international students in collectivistic contexts. Thus, these culturally specific factors suggested different relationships between acculturation modes and outcomes of Chinese students studying in Japan, as demonstrated in previous studies. According to a study conducted by Sun (2013) on Chinese students studying in Japan, integration was not associated with psychological adjustment in spite of being seen as the most preferred mode. Han (2004) discussed that for some international students from China, ethnocentrism might have led to rejection of acculturation to the host country and therefore interfered with their adaption. When examining the modes of acculturation from two underlying cultural dimensions, Hayashi (1997) revealed that only acculturation to the host culture could directly predict acculturation outcomes for East Asian international students in Japan. Exploring the acculturation of Chinese international students in collectivistic contexts may provide the cross-cultural validity for Berry et al.'s (1987) acculturation framework.

\section{Attachment and Acculturation}

The other major topic of this study pertained to the effects of attachment styles on the cultural adaptation of overseas Chinese students. According to attachment theory (Bowlby, 1988), children or adults with secure attachment to caregivers are most capable of exploring the physical or social environment. Anxiety and avoidance are conceptualized as two dimensions underlying insecure attachment (Brennan et al., 1998). Individuals with high attachment anxiety or avoidance are likely to be afraid of being rejected and abandoned or being intimate and dependent (Brennan et al., 1998). Attachment exerts an influence on many facets of an individual's various life transitions, like the adjustment process of college students in western countries (e.g., Wei et al., 2005). Freshmen with a high level of attachment anxiety reported feelings of loneliness and depressive symptoms (Wei et al., 2005). Previous research findings also showed greater selfconfidence in college students with secure attachment (low attachment avoidance and anxiety), which was associated with better learning and social and emotional adaptation (Lopez \& Gormley, 2002; Mattanah et al., 2004).

Recently, researchers have argued that an individual's adult attachment style, a psychological characteristic, acted as a moderator in Berry et al.'s (1987) model and could account for the adjustment outcomes of overseas students (e.g., Chen et al., 2002; Wang \& Mallinckrodt, 2006). Attachment researchers have indicated 
that international students studying abroad have to physically leave their loved ones in home nations, a journey that is similar to the process in which infants attempt to explore the physical environments around them (Wang \& Mallinckrodt, 2006). Thus, to promote successful adaptation, students could benefit from immersing themselves in the new surroundings in host countries. Empirical research has shown that international students who come from East Asia and study in the United States with secure attachment are able to regulate anxiety and develop a network of new supportive friendships (Chen et al., 2002). For Asian international students in the United States, parental and professor attachment buffer against acculturative stress (Han et al., 2017). Gouin and MacNeil (2019) revealed that attachment anxiety led to increased health risk through weakened immune system in the acculturation process. Wang and Mallinckrodt (2006) also found that attachment anxiety and avoidance were the significant positive predictors of the mental and sociocultural adaptation of international students from a Chinese cultural background who were studying in the United States. This study puts forward the hypothesis that students from China who are high in attachment avoidance and anxiety would encounter more adjustment difficulties while studying in Japan.

Studies have investigated the relationship between the styles of attachment and two cultural dimensions (e.g., Wang \& Mallinckrodt, 2006). For example, one study showed a negative correlation between attachment anxiety and acculturation of students to the host culture among international students from Chinese cultural backgrounds in America (Wang \& Mallinckrodt, 2006). While previous research indicated that low levels of anxiety and avoidance were beneficial for individuals to explore and adapt to host individualistic contexts, it is unclear whether or to what extent such a relation holds in collectivistic contexts.

\section{Current Study}

Given the theoretical and practical needs of research on the acculturation of Chinese students studying in Japan, this study selected Chinese students studying in Japan as research participants to examine how acculturation modes and attachment styles would predict their adjustment outcomes. However, it should be first noted that this study focused on two distinct outcomes of acculturation, namely psychological and sociocultural adjustment (Ward \& Kennedy, 1994). The former referred to mental and emotional health while the latter referred to the capability of acquiring and performing culturally proper behavioral competence and social skills to integrate into the host culture (Ward \& Kennedy, 1994). This study argued that both outcomes were of importance to the mental health and academic success of Chinese international students, and thus included them as adjustment outcomes.

Four hypotheses on the processes and outcomes of acculturation of Chinese students studying in Japan were proposed in this study. First, Chinese students studying in Japan would have better adjustment outcomes than their counterparts in the United States in both the sociocultural and psychological domains (Hypothesis 1). The cultural adaptation of an individual is affected by the cultural 
differences between host and home cultures (Berry, 2003; Ward et al., 2001). According to the studies conducted in western societies, students from Asia found it more challenging to adapt to the host culture compared with other groups due to larger cultural differences. Supporting this, Yeh and Inose (2002) indicated that Chinese, Korean, and Japanese international students studying in western societies were especially challenged by the differences between collectivism and individualism. Since China shares similarities with Japan in culture and both are collectivist societies, students from China would encounter fewer difficulties during the acculturation process in Japan (Inoue \& Merino, 2007). In addition, with the progress of multicultural coexistence policy (e.g., increased multilingual information and advisory services) promoted by Japan's government, more and more international students are reporting Japan as convenient and safe with regard to daily life (Han, 2004).

The second hypothesis proposed that identifying with the home culture and adapting to the host culture would be positively associated with the adjustment outcomes of Chinese students studying in Japan. As Japanese culture has the expectation of within-group homogeneity (e.g., Nagy, 2012), we hypothesized that cultural adaptation to the host country would be associated with less psychological distress and difficulties in sociocultural adjustment. On the other hand, identifying with the home culture would negatively predict adjustment outcomes (Hypothesis 2).

As for the third hypothesis, previous research highlighted the influence of attachment styles on the acculturation process of overseas students in western societies (e.g., Chen et al., 2002). A previous study indicated that securely attached overseas students showed greater perception of social support from others in the home and host countries, felt less psychologically distressed, and reported fewer difficulties in sociocultural adjustment (Chen et al., 2002). Therefore, the current study proposed that high attachment avoidance and anxiety would predict more psychological distress and difficulties in sociocultural adjustment (Hypothesis 3).

The last hypothesis proposed a negative correlation between attachment anxiety and avoidance and acculturation to the host culture (Hypothesis 4). Because securely attached individuals would tend to fully explore a new cultural environment and report higher cultural adaptation to the host country (Wang \& Mallinckrodt, 2006), those with insecure attachment were expected to encounter more difficulties in adjusting to the host culture.

\section{METHOD}

\section{Participants and Procedures}

With the help of the international student support organizations, we sent an email invitation to Chinese international students in various universities in the Kanto region as well as to Chinese international student associations in Kanto Region. The email described the research purpose and contained the link of the online survey. When participants clicked the survey link, they were first directed 
to the informed consent form prior to the study's questionnaire. Anonymity was assured. Respondents were given the option to quit the survey at any time. The entire survey took approximately $20 \mathrm{~min}$.

A total of 316 individuals participated. Among these, we excluded 39 individuals from the final analysis who responded only to the demographic questions. One response was removed because the respondent was under age 18 . Thus, we used a total of 277 responses to test the hypotheses, and none of them included missing data. About $67 \%$ participants identified as female and $33 \%$ of the participants identified as male. The mean age of the participants was 24.18 years $(S D=3.1$, range 18-38 years). All participants reported their country of origin as Mainland China. This sample consisted of 117 graduate students (42\%) and 160 undergraduates $(58 \%)$. The majority of the students reported that their length of time in Japan was longer than 4 years $(27.4 \%)$, followed by $2-3$ years (19.9\%), $1-2$ years $(18.8 \%)$, less than 6 months $(14.1), 3-4$ years $(11.2 \%)$, and 6 months to 1 year $(8.7 \%)$. Almost $70.8 \%$ of the participants reported their Japanese proficiency as good, $29.2 \%$ of the participants reported their Japanese proficiency as fair, and none of participants reported their Japanese as low or excellent.

\section{Measures}

Participants completed an online survey in both Mandarin Chinese and traditional Chinese in 2015. It contained the following measures.

\section{Experiences in Close Relationships Scale}

In this study, the adult attachment was assessed by the Experienced in Close Relationships Scale (ECRS; Brennan et al., 1998) using the Chinese version (Mallinckrodt \& Wang, 2004). This scale consists of two attachment subscalesattachment anxiety and avoidance - each of which comprises a total of 18 items with responses given on a 7-point Likert scale (ranging from $1=$ strongly disagree to $7=$ strongly agree). The scales were reliable and valid, which was repeatedly verified in both English and Chinese (e.g., Brennan et al., 1998; Mallinckrodt \& Wang, 2004). The internal reliability of the scale of the Chinese version was reported as .91 and .88 for attachment avoidance and anxiety, respectively (Mallinckrodt \& Wang, 2004). In this study, Cronbach's alpha was .91 and .92 for attachment avoidance and anxiety, respectively.

\section{Acculturation Index}

With two independent subscales of cultural identification with the native (Chinese) culture and cultural adaptation to the host (Japanese) culture, the Acculturation Index (AI; Ward \& Kennedy, 1994) consisted of 21 items that measured three aspects, including values, cognition, and behavior. The respondents indicated how similar their various experiences of daily life were compared with Chinese and Japanese cultures by means of a 6-point response scale (ranging from $1=$ not at all similar to $6=$ very similar). The scales were 
reliable and valid, which was demonstrated in previous research on Chinese international students in western countries (e.g., Wang \& Mallinckrodt, 2006). We adopted translation and back-translation methods to translate theAI into Chinese. In this study, Cronbach's alpha was .96 and .93 for the two subscales including the native (Chinese) culture and the host (Japanese) culture, respectively.

\section{Socio-Cultural Adaptation Scale}

We used the Socio-Cultural Adaptation Scale (SCAS; Ward \& Kennedy, 1999) to assess the level of sociocultural adjustment. The SCAS measured the degree of difficulties caused by cultural differences and experienced by individuals in behavior and cognition. Ward and Kennedy (1999) indicated that the SCAS was flexible as an instrument and could be modified based on the characteristics of sojourners as samples. This scale has been shown to be highly reliable in numerous cultural contexts. In a previous study, 25 cultural-general items that represent three subscales (survival, academic adaptation, and interpersonal adaptation) most relevant for the international students in Japan were selected (Simic-Yamashita \& Tanaka, 2010). The respondents evaluated each item by indicating the degree of difficulties they experienced in a variety of sociocultural situations using a 5-point scale varying from 1 (not difficult) to 5 (extremely difficult). We completed the English-Chinese translation of items by adopting the back-translation method of bilingual researchers. In this study, coefficient alphas were $.91, .71, .80$, and .67 for the total scale, survival, academic adaptation, and interpersonal adaptation, respectively.

\section{Brief Symptom Inventory 18}

This study used the Brief Symptom Inventory (BSI-18; Derogatis \& Savitz, 2000) to measure psychological distress. This scale has 18 items for measuring three dimensions of psychiatric disorders, including anxiety, depression, and somatization (six items for each). The participants reported the level of their different symptoms in the past week by means of a 4-point scale (ranging from 1 $=$ not at all to 4 =quite $a$ bit). Previous studies used this scale with a sample of Chinese students studying in the United States and reported .88 for internal reliability (Wang \& Mallinckrodt, 2006). The validity of the BSI-18's Chinese version was demonstrated in drug abusers in Mainland China (Wang et al., 2013). In this study, internal reliability was .93 and varied from .78 to .86 for the total scale and three subscales, respectively.

\section{International Comparison Data}

In addition to exploring the relationship between attachment, acculturation, and psychosocial adjustment of Chinese international students in Japan, the current research also compared Chinese international students in Japan to their counterparts in the United States. While a considerable body of measurement has 
been developed to capture international students' adaptation, especially in the sociocultural domain (e.g., Sun, 2013), researchers have argued for the importance of consistency in measurements in understanding international students' acculturation holistically (Takai, 1989; Tan et al., 2011). The validation of the SCAS (Ward \& Kennedy, 1999) and BSI-18 (Derogatis \& Savitz, 2000) in international students has been established in the United States and Japan (Wang \& Mallinckrodt, 2006; Simic-Yamashita \& Tanaka, 2010). Thus, in the current research we compared our results with those of Chinese international students in the United States using data from Wang and Mallinckrodt (2006). Their study was chosen as a reference because it was the only one to our knowledge that used the same measures as the current study and offered a fair comparison point.

\section{RESULTS}

\section{Preliminary Analysis}

We computed descriptive statistics for all variables. Table 1 summarizes the means, standard deviations, and bivariate correlations between the variables under study. We conducted normality tests and found normal skewness (ranged from .07 to .95 ) and kurtosis (ranged from .53 to .70 ). Correlations for the primary measures indicated that length of time in Japan $(r=-.2, p<.001)$ and students' self-reported Japanese ability $(r=-.42, p<.001)$ were both significantly negatively associated with sociocultural adjustment, but they were not significantly correlated with psychological distress. Additionally, sociocultural adjustment was found to be significantly positively correlated with psychological distress $(r=.49, p<.001)$.

\section{Testing of Research Hypotheses}

Hypothesis 1 stated that Chinese international students in Japan would have a better adjustment outcome than those in the United States in sociocultural and psychological domains. To test this hypothesis, we made a comparison of psychological distress and sociocultural adjustment difficulties between the two student groups in Japan and the United States by conducting an independent samples $t$ test. According to the results, Chinese students studying in Japan had fewer social adjustment difficulties, $t(379)=2.99, p<.01$, yet higher psychological distress, $t(379)=4.68, p<.001$, compared with their counterparts in the United States.

Hypothesis 2 posited that psychological distress and sociocultural adjustment difficulties would be negatively related to acculturation to the host culture and positively related to identification to the home culture. Hypothesis 3 stated that individuals with a high level of attachment avoidance and anxiety would have more psychological distress and sociocultural adjustment difficulties. In order to test Hypotheses 2 and 3, we used psychological distress and sociocultural adjustment difficulties as dependent variables to perform two groups of two-step hierarchical multiple regression separately (Table 2 ). 
Table 1: Correlations of Demographic, Attachment, Acculturation, and Psychosocial Adjustment Variables

\begin{tabular}{|c|c|c|c|c|c|c|c|c|c|c|}
\hline Variable & $M$ & $S D$ & 1 & 2 & 3 & 4 & 5 & 6 & 7 & 8 \\
\hline $\begin{array}{l}\text { Length of } \\
\text { stay }\end{array}$ & 4.02 & 1.84 & - & $0.30^{* *}$ & 0.05 & 0.19 & 0.14 & 0.11 & 0.10 & 0.11 \\
\hline $\begin{array}{l}\text { Japanese } \\
\text { proficiency }\end{array}$ & 1.30 & 0.46 & & - & 0.17 & 0.04 & 0.10 & 0.16 & 0.10 & $0.36^{* *}$ \\
\hline $\begin{array}{l}\text { Attachment } \\
\text { avoidance }\end{array}$ & 3.43 & 1.03 & & & - & $0.21^{*}$ & 0.19 & 0.08 & $0.29^{* *}$ & $0.27^{* *}$ \\
\hline $\begin{array}{l}\text { Attachment } \\
\text { anxiety }\end{array}$ & 3.86 & 1.22 & & & & - & 0.11 & 0.10 & $0.40^{* * *}$ & $0.38^{* * *}$ \\
\hline $\begin{array}{l}\text { Identification } \\
\text { with Chinese } \\
\text { culture }\end{array}$ & 3.78 & 1.09 & & & & & - & 0.18 & 0.20 & 0.01 \\
\hline $\begin{array}{l}\text { Acculturation } \\
\text { to Japanese } \\
\text { culture }\end{array}$ & 3.14 & 0.89 & & & & & & - & 0.02 & $0.21^{* * *}$ \\
\hline $\begin{array}{l}\text { Psychological } \\
\text { distress }\end{array}$ & 1.86 & 0.66 & & & & & & & - & $0.49^{* *}$ \\
\hline $\begin{array}{l}\text { Sociocultural } \\
\text { adjustment } \\
\text { difficulties }\end{array}$ & 1.70 & 0.52 & & & & & & & & - \\
\hline
\end{tabular}

Note. ${ }^{*} p<.05 ; * * p<.01 ; * * * p<.001$.

Table 2: Hierarchical Regression Analyses of Psychological Adjustment

\begin{tabular}{|c|c|c|c|c|}
\hline \multirow{3}{*}{$\begin{array}{l}\text { Variable } \\
\text { Gender }\end{array}$} & \multicolumn{4}{|c|}{ Psychosocial adjustment $(\mathrm{N}=277)$} \\
\hline & \multicolumn{2}{|c|}{$\begin{array}{l}\text { Psychological } \\
\text { distress }(\beta)\end{array}$} & \multicolumn{2}{|c|}{$\begin{array}{c}\text { Sociocultural } \\
\text { adjustment difficulties } \\
(\beta)\end{array}$} \\
\hline & -.06 & .00 & $-.13 *$ & -.09 \\
\hline Japanese abilities & $-.14 *$ & $-.11 *$ & $-.26 * * *$ & -.09 \\
\hline Length of residence & $.13^{*}$ & .19 & $-.14 *$ & -.18 \\
\hline Attachment avoidance & & $.20 * * *$ & & $.15^{* *}$ \\
\hline Attachment anxiety & & $.45^{* * *}$ & & $.35 * * *$ \\
\hline Acculturation to host culture & & .01 & & $-.19 * * *$ \\
\hline $\begin{array}{l}\text { Identification with host } \\
\text { culture }\end{array}$ & & -.03 & & .05 \\
\hline$R^{2}$ & .03 & .29 & .12 & .32 \\
\hline$\Delta R^{2}$ & .03 & $.26^{* * *}$ & $.12 * * *$ & $.2 * * *$ \\
\hline
\end{tabular}

Note. ${ }^{*} p<.05 ; * * p<.01 ; * * * p<.001$.

As revealed by the hierarchical multiple regression, gender, Japanese proficiency, and duration of stay in Japan had no significant effects on the regression model of sociocultural adaptation in the first step and accounted for 
$3 \%$ of the variation. However, Japanese proficiency and duration of stay in Japan produced significant effects on the regression model of psychological distress.

The introduction of attachment and acculturation variables in step two additionally explained $20 \%$ of the variance in sociocultural adjustment and $26 \%$ in psychological distress, which partly supported Hypothesis 2- that is, only acculturation to Japanese culture significantly predicted sociocultural adjustment difficulties, while acculturation variables were not significant predictors of psychological distress. These results supported Hypothesis 3 in that attachment anxiety and avoidance significantly predicted psychological distress and sociocultural adjustment difficulties.

Hypothesis 4 proposed a negative correlation between attachment anxiety and avoidance and acculturation to the host culture, which was tested by conducting a Pearson product-moment correlation. As shown in Table 1, no significant correlations were found between attachment anxiety $(r=-.10, p=.33)$ and avoidance $(r=-.08, p=.48)$ and acculturation to the host culture.

\section{DISCUSSION}

This study had two objectives. The first was to capture the adjustment outcomes of Chinese international students in Japan by comparing them with those in the United States. The second one aimed to examine whether identification to home versus host culture and attachment predicted the psychosocial adjustment of Chinese international students. Four significant findings were revealed. First, Chinese international students in Japan had better outcome than those in America in sociocultural adjustment rather than psychological adjustment. Second, both attachment avoidance and anxiety significantly predicted psychological and sociocultural adjustment difficulties. Third, a positive correlation was found only between acculturation to the host culture and sociocultural adjustment difficulties. Fourth, no relationships were found between acculturation to the host culture and attachment anxiety and avoidance.

A comparison of Chinese students studying in Japan and the United States showed significant differences in both domains of psychosocial adjustment. As predicted, the findings indicated that Chinese students studying in Japan encountered fewer sociocultural adjustment difficulties than those in the United States. The sociocultural adjustment could be promoted by many factors such as the supportive environment including physical and informative support in the host country. Chinese international students in Japan reported that "Public transportation is very convenient and safe," "Daily life is very convenient," and "Information about a variety of services is well provided" in Japan (Han, 2004). Thus, it might be said that Japan generally provided a good supportive environment for this specific group of international students in terms of food, clothing, and living, which could also be facilitated by the similarities shared between China and Japan. However, it was found that Chinese students studying in Japan encountered more difficulties than those in the United States with regard to psychological distress. The psychological and sociocultural adjustment were conceptually distinct but empirically related to some extent (Berry, 2003). 
Specifically, previous research suggested that the sociocultural adjustment of individuals originating from cultures similar to the host culture was likely to influence their psychological adjustment due to the strong correlation between the two domains of adjustment (Berry et al., 2006). Furthermore, this study suggested that Chinese international students still experienced more psychological distress than those in the United States while encountering fewer difficulties in sociocultural adjustment, indicating that additional factors might influence the mental health of Chinese international students.

We hypothesized that more acculturation to Japanese culture and less identification with Chinese culture would both lead to better acculturation outcomes. However, the current findings suggested that only acculturation to Japanese culture significantly predicted the sociocultural adjustment of Chinese students; furthermore, two domains of the acculturation mode were not predictors of the psychological adjustment of this student group after controlling for the influence of Japanese proficiency and duration of stay. We offer several speculations on the results. Han (2004) posited ambivalent attitudes toward Japan as one characteristic of international students from China and proposed that such attitudes led to their maladjustment. Previous qualitative research on Chinese students in Japan has also suggested that their expectations for and ambivalent emotions toward acculturation to Japanese culture were one of the important factors affecting their adjustment (Yin \& Aoki, 2018). Based on the results, the current study highlighted the important interaction between host and home cultures and provided a culture-specific (rather than universal) acculturation map for Chinese international students in Japan. That is to say, while understanding Japanese culture could improve their sociocultural adjustment, efforts directly made toward facilitating their identification with both home culture and host culture might not always lead to the desired psychological adjustment outcome. For clinician or faculty who work with Chinese students struggling with acculturation, clarifying their attitude toward both cultures and acknowledging their potential ambivalent feelings might encourage them to fully take steps toward resolving acculturation difficulties.

This study showed that the attachment of Chinese international students plays a role in their acculturation process in Japan's collectivistic society. After controlling for the effects of gender, Japanese proficiency, and duration of stay, attachment avoidance and anxiety remained significant predictors of psychological and sociocultural adjustment difficulties. Consistent with findings of international students in individualistic cultures, these findings suggested that attachment was critical to Chinese students' adjustment in Japan. We also note that attachment was the only factor influencing students' psychological adjustment among all the factors involved in the current study. Based on these findings, institutions or organizations should take attachment into consideration when supporting this student group. Outreach/psychoeducational programs and individual interventions focusing on attachment can be recommended to Chinese international students in Japan. Clinicians who work with international students can initiate outreach activities to provide students with on-campus resources of psychotherapy. In addition, psychoeducation on the benefits of psychotherapy as 
well as the acculturation process can promote students' self-awareness and helpseeking behavior. Furthermore, research needs to explore other factors contributing to the psychological adaptation of Chinese students.

\section{Limitations and Suggestions for Future Research}

The current study has several limitations. First, the cross-sectional design made it impossible to strictly infer the causality among the variables. Additional studies are needed that employ a longitudinal design to cross-validate the effects of attachment and acculturation over time. Second, existing factors predicting the psychological adjustment of Chinese international students in Japan remain limited. More studies need to be carried out to explore and explain factors influencing the psychological adjustment of the student group in Sino-Japan relationship and Japanese contexts. Third, online questionnaires were distributed by student organizations and completed by voluntary participants in Kanto Region. Thus, participants in this study might not represent the general population.

\section{CONCLUSION}

The present study revealed an important relationship among the attachment, acculturation, and adjustment outcomes of international students from China in a collectivistic cultural background, which significantly contributes to the literature by showing a culturally universal role of attachment and a culturally specific role of acculturation in Chinese international students' adjustment in Japan.

\section{REFERENCES}

An, Y., \& Nagai, S. (2019). Factors related to help-seeking process of Chinese international students in depressed situation: Comparing Chinese international students studying at language school to Japanese university students. Japanese Journal of Community Psychology, 23(1), 34-51.

Berry, J. W. (2003). Conceptual approaches to acculturation. In K. M. Chun, P. B. Organista, \& G. Marin (Eds.), Acculturation: Advances in theory, measurement, and applied research (pp. 17-38). American Psychological Association.

Berry, J. W., Kim, U., Minde, T., \& Mok, D. (1987). Comparative studies of acculturative stress. International Migration Review, 21(3), 491-511.

Berry, J. W., Phinney, J. S., Sam, D. L., \& Vedder, P. (2006). Immigrant youth: Acculturation, identity, and adaptation. Applied Psychology: An International Review, 55(3), 303-332. https://doi.org/10.1111/j.14640597.2006.00256.x

Bond, M. H. (2002). Reclaiming the individual from Hofstede's ecological analysis-A 20-year odyssey: Comment on Oyserman et al. (2002). Psychological Bulletin, 128(1), 73-77. https://doi.org/10.1037/00332909.128.1.73 
Bourhis, R. Y., Moïse, L. C., Perreault, S., \& Senécal, S. (1997). Towards an interactive acculturation model: A social psychological approach. International Journal of Psychology, 32(6), 369-386. https://doi.org/10.1080/002075997400629

Bowlby, J. (1988). A secure base: Parent-child attachment and healthy human development. Basic Books.

Brennan, K. A., Clark, C. L., \& Shaver, P. R. (1998). Self-report measurement of adult attachment: An integrative overview. In J. A. Simpson \& W. S. Rholes (Eds.), Attachment theory and close relationships (pp. 46-76). Guilford Press.

Center for China and Globalization. (2018). Annual report on the development of Chinese studying abroad 2017. Social Science Academic Press.

Chen, H.-J., Mallinckrodt, B., \& Mobley, M. (2002). Attachment patterns of East Asian international students and sources of perceived social support as moderators of the impact of U.S. racism and cultural distress. Asian Journal of Counselling, 9(1-2), 27-48.

Chen, J., \& Zhou, G. (2019). Chinese international students' sense of belonging in North American postsecondary institutions: A critical literature review. Brock Education: A Journal of Educational Research and Practice, 28(2), 48-63. https://doi.org/10.26522/brocked.v28i2.642

Derogatis, L. R., \& Savitz, K. L. (2000). The SCL-90-R and Brief Symptom Inventory (BSI) in primary care. In M. E. Maruish (Ed.), Handbook of psychological assessment in primary care settings (pp. 297-334). Lawrence Erlbaum Associates.

Ge, W. (2007). Cross-cultural adaptation of Chinese students and technical trainees in Japan. Keisuisha.

Gouin, J.-P., \& MacNeil, S. (2019). Attachment style and changes in systemic inflammation following migration to a new country among international students. Attachment \& Human Development, 21(1), 38-56. https://doi.org/10.1080/14616734.2018.1541515

Han, I. (2004). Psychological study about the maladjustment and inferiority complex of Chinese students in Japan. The Sanyo Review, 11, 105-125. https://doi.org/10.24598/sanyor.11.0_105

Han, S., Pistole, M. C., \& Caldwell, J. M. (2017). Acculturative stress, parental and professor attachment, and college adjustment in Asian international students. Journal of Multicultural Counseling and Development, 45(2), 111126. https://doi.org/10.1002/jmcd.12068

Hayashi, S. (1997). The effects of self-perception and attitudes to cultures on international students' feeling of adjustment. The Japanese Journal of Psychology, 68(5), 346-354.

Hofstede, G. (1980). Culture's consequences: International differences in workrelated values. SAGE.

Hofstede, G. (1993). Cultural constraints in management theories. Academy of Management Executive, $\quad 7(1), \quad 81-94$. http://dx.doi.org/10.5465/ame.1993.9409142061 
Inoue, N., \& Merino, A. C. (2007). Intercultural academic adjustment of Japanese government scholarship students: A multiple case study at Kyushu University. Kyushu Communication Studies, 5, 61-74.

Japan Student Services Organization. (2018). International students in Japan 2017. Retrieved from http://www.jasso.go.jp

Jou, Y-H., \& Fukada, H. (2011). The influence of stress and social support on the mental and physical health of Chinese students in Japan: Was there change in seventeen years? International Students Education, 16, 1-12.

Lee, J. S. (2017). Challenges of International students in a Japanese university: Ethnographic perspectives. Journal of International Students, 7(1), 73-93. https://doi.org/10.32674/jis.v7i1.246

Lopez, F. G., \& Gormley, B. (2002). Stability and change in adult attachment style over the first-year college transition: Relations to self-confidence, coping, and distress patterns. Journal of Counseling Psychology, 49(3), 355364. https://doi.org/10.1037/0022-0167.49.3.355

Ma, B. (2007). The relationship between mental health status and psychosociological factors among Chinese postgraduate students in Japan. Juntendo University Medicine, 53, 200-210.

Mallinckrodt, B., \& Wang, C.-C. (2004). Quantitative methods for verifying semantic equivalence of translated research instruments: A Chinese version of the experiences in close relationships scale. Journal of Counseling Psychology, 51(3), 368-379. https://doi.org/10.1037/0022-0167.51.3.368

Mattanah, J. F., Hancock, G. R., \& Brand, B. L. (2004). Parental attachment, separation-individuation, and college student adjustment: A structural equation analysis of mediational effects. Journal of Counseling Psychology, 51(2), 213-225. https://doi.org/10.1037/0022-0167.51.2.213

Muthukrishna, M., Bell, A., Henrich, J., Curtin, C., Gedranovich, A., McInerney, J., \& Thue, B. (2018). Beyond WEIRD psychology: Measuring and mapping scales of cultural and psychological distance. SSRN. http://dx.doi.org/10.2139/ssrn.3259613

Nagy, S. R. (2012). Japanese-style multiculturalism? A comparative examination of Japanese multicultural coexistence. Japan Journal of Multilingualism and Multiculturalism, 18(1), 1-18.

Organisation for Economic Cooperation and Development. (2017). Education at a glance 2017: Indicators. https://doi.org/10.1787/eag-2017-en

Simic-Yamashita, M., \& Tanaka, T. (2010). Exploratory factor analysis of the Sociocultural Adaptation Scale (SCAS) among international students in Japan. Journal of Humanities and Social Sciences, 29, 206-195

Sullivan, C., \& Kashubeck-West, S. (2015). The interplay of international students' acculturative stress, social support, and acculturation modes. Journal of International Students, 5(1), 1-11.

Sun, Y. (2013). Chinese students in Japan: The mediator and the moderator between their personality and mental health. International Journal of Psychology, 48(3), 215-223. https://doi.org/10.1080/00207594.2011.648942

Suzuki, E. (2007). The present of multicultural in Japan. in T. Menju \& E. Suzuki (Eds.), Introductory course 4 for cooperative activities exchange: 
Multicultural power-overcoming multicultural coexistence (pp. 14-39). Akashi Shoten.

Takai, J. (1989). An overview of international student adjustment studies in Japan. Bulletin of the School of Education Psychology, 36, 139-147. https:// doi.org/10.18999/bulfep.36.139

Tan, H., Watanabe, T., \& Konno, H. (2011). A review of psychological studies on the cross-cultural adaptation of international students in Japan. Mejiro University Psychology Studies, 7, 95-114.

Tanaka, T., Tkai, J., Kohyama, T., \& Fujhihara, T. (1994) Adjustment patterns of international students in Japan. International Journal of Intercultural Relations, 18(1), 55-75. https://doi.org/10.1016/0147-1767(94)90004-3

Wang, C.-C. D., \& Mallinckrodt, B. (2006). Acculturation, attachment, and psychosocial adjustment of Chinese/Taiwanese international students. Journal of Counseling Psychology, 53(4), 422-433. https://doi.org/10.1037/0022-0167.53.4.422

Wang, J., Kelly, B. C., Liu, T., Zhang, G., \& Hao, W. (2013). Factorial structure of the brief symptom inventory (BSI)-18 among Chinese drug users. Drug and Alcohol Dependence, 133(2), 368-375. https://doi.org/10.1016/j.drugalcdep.2013.06.017

Ward, C., Bochner, S., \& Furnham, A. (2001). The psychology of culture shock (2nd ed.). Routledge.

Ward, C., \& Kennedy, A. (1994). Acculturation strategies, psychological adjustment, and sociocultural competence during cross-cultural transitions. International Journal of Intercultural Relations, 18(3), 329-343. https://doi.org/10.1016/0147-1767(94)90036-1

Ward, C., \& Kennedy, A. (1999). The measurement of sociocultural adaptation. International Journal of Intercultural Relations, 23(4), 659-677. https://doi.org/10.1016/S0147-1767(99)00014-0

Ward, C., \& Lin, E.-Y. (2010). There are homes at four corners of the seas: Acculturation and adaptation of overseas Chinese. In M. H. Bond (Ed.), The Oxford handbook of Chinese psychology (pp. 657-677). Oxford University Press.

Wei, M., Russell, D. W., \& Zakalik, R. A. (2005). Adult attachment, social selfefficacy, self-disclosure, loneliness, and subsequent depression for freshman college students: A longitudinal study. Journal of Counseling Psychology, 52(4), 602-614. https://doi.org/10.1037/0022-0167.52.4.602

$\mathrm{Wu}, \mathrm{X}$. (2017). A review of social network studies for international students in Japan. Integrated Sciences for Global Society Studies, 6, 29-39.

Yasuda, T. (2011). The fantasy of multilingual society: Reconsidering the history of modern Japanese language. Sangensha.

Yeh, C., \& Inose, M. (2002). Difficulties and coping strategies of Chinese, Japanese, and Korean immigrant students. Adolescence, 37(145), 69-82.

Yeh, C. J., \& Inose, M. (2003). International students' reported English fluency, social support satisfaction, and social connectedness as predictors of acculturative stress. Counselling Psychology Quarterly, 16(1), 15-28. https://doi.org/10.1080/0951507031000114058 
Yin, M., \& Aoki, K. (2018). A qualitative study about the cross-cultural adaptation of Chinese international students in Japan. Bulletin of Center of Clinical Psychology \& Counseling at Ochanomizu University, 19, 49-59.

MENGXI YIN is a doctoral student in the Department of Counseling Psychology at Cleveland State University. Her major research interests lie in the area of crosscultural adjustment. Email: $\underline{\text { m.yin@vikes.csuohio.edu }}$

KIKUYO AOKI, $\mathrm{PhD}$, is an associate professor in clinical and developmental psychology at Ochanomizu University. She studies attachment, mother-infant emotional interactions and school mental health. Email: aokiku@jcom.home.ne.jp

KELLY YU-HSIN LIAO, $\mathrm{PhD}$, is an assistant professor in the doctoral specialization in Counseling Psychology at Cleveland State University. She studies minority-related stress, positive psychology, and health psychology in ethnic minorities. Email: y.liao54@csuohio.edu

HUI XU, $\mathrm{PhD}$, is an assistant professor in counseling psychology at Loyola University Chicago. His scholarship focuses on vocational, counseling science, assessment, and cross-cultural issues. Email: hxu2@luc.edu 